\title{
Case Report \\ Schwannoma of the Tongue in a Paediatric Patient: A Case Report and 20-Year Review
}

\author{
Nitin Bhola, Anendd Jadhav, Rajiv Borle, Gaurav Khemka, \\ Umesh Bhutekar, and Sanatan Kumar
}

Department of Oral and Maxillofacial Surgery, Sharad Pawar Dental College and Hospital, Wardha, Maharashtra 442004, India

Correspondence should be addressed to Umesh Bhutekar; bhutekarumesh@gmail.com

Received 26 March 2014; Revised 4 June 2014; Accepted 29 June 2014; Published 14 July 2014

Academic Editor: Danyel E. Da Cruz Perez

Copyright (C) 2014 Nitin Bhola et al. This is an open access article distributed under the Creative Commons Attribution License, which permits unrestricted use, distribution, and reproduction in any medium, provided the original work is properly cited.

\begin{abstract}
Schwannomas (Neurilemmomas) are benign, encapsulated, slow-growing, and usually solitary tumours originating from Schwann cells of the peripheral nerve sheath with uncertain etiology. Approximately $25-48 \%$ of cases are seen in the head and neck region, of which $1 \%$ appears in the oral cavity. Lingual schwannoma can affect all age groups with peak incidence between the third and sixth decade. We report a rare case of lingual schwannoma in a 14-year-old girl complaining of asymptomatic swelling over lateral border of tongue since two years. Clinical examination revealed a nodule $1.5 \times 1 \mathrm{~cm}$ in size, rubbery, nontender, smooth at right lateral border of tongue covered by normal mucosa, with no cervical lymphadenopathy. Excisional biopsy of the lesion was done under local anaesthesia. The histological sections spindle cells with thin wavy nuclei arranged as typical Antoni A (with Verocay bodies) and Antoni B areas. Nuclear palisading distribution (typical of a schwannoma) was readily identifiable. The patient was recurrence-free after one year.
\end{abstract}

\section{Introduction}

Schwannoma, also called neurilemmoma, is a solitary, benign, encapsulated, and slow growing tumor, arising from the neural sheath's Schwann cells of the peripheral, cranial (except for the optic and olfactory), spinal, and autonomic nerves [1]. Schwann cells form a thin outline around each extracranial nerve fiber and wrap larger fibers with an insulating membrane, myelin sheath, to enhance nerve conductance. As nerves exit the brain and spinal cord, there is a transition from myelination by oligodendrocytes to myelination by Schwann cells. Schwannomas arise when proliferating Schwann cells form a tumor mass encompassing motor and sensory peripheral nerves.

The cause of the tumor is unknown. However, some etiological factors are conjectured, such as spontaneous growth, external injury, chronic irritation, or exposure to radiation [2]. Approximately $25-48 \%$ arises in the head and neck region [3]. Schwannoma accounts for just over $1 \%$ of benign tumours reported in the oral cavity; they are the most commonly encountered nerve sheath tumours in this location [4]. Peripherally, the commonest location is the tongue [5], followed by the palate, floor of mouth, buccal mucosa, and mandible. Only 50\% of these tumors have a direct relation with a nerve. In the tongue, the distinction between hypoglossal, glossopharyngeal, and lingual nerve origin is difficult, given their proximity. The peak incidence is between the third and sixth decades, with no predilection for gender or race [6].

The size and locations of lesions determine the presence and intensity of symptoms. The tumour is normally solitary, smooth-surfaced, slow growing, and generally asymptomatic. It may occasionally cause pain or discomfort. The goal of treatment is complete excision, which results in low rates of recurrence [7]. Malignant transformation is rare and incidence of malignant schwannomas ranges from $8 \%$ to $13.9 \%$ [8]. The following case is a rare case report of a lesion occurring in the tongue of a 14-year-old girl as the peak incidence of occurrence is between the third and sixth decade of life. 


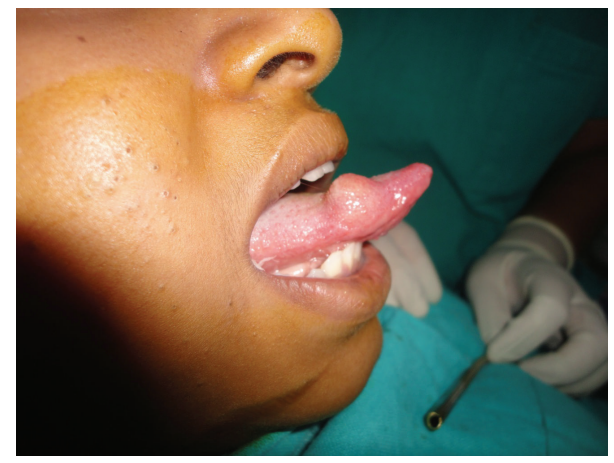

Figure 1: Asymptomatic nodule over right anterolateral side of tongue.

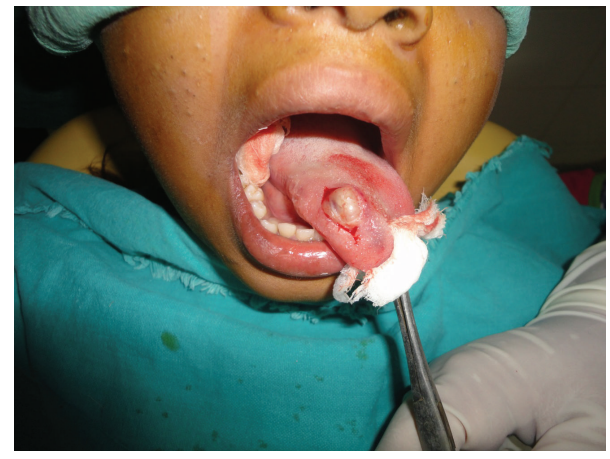

FIGURE 2: Encapsulated mass.

\section{Case Report}

A 14-year-old girl presented to the department of oral and maxillofacial surgery for evaluation of a slow growing, occasionally painful nodule on right anterolateral side of tongue first noted 2 years back (Figure 1). Clinical examination revealed a nodule $1.5 \times 1 \mathrm{~cm}$ in size, rubbery, nontender, and smooth at right lateral border of tongue covered by normal mucosa; no cervical lymphadenopathy was evident.

Patient had no difficulty in chewing, swallowing, and phonation and there was no sensory or taste abnormalities by the patient. The remaining physical examination was unremarkable. The differential diagnosis included traumatic fibroma, neurofibroma, and benign lesions like tumors of salivary gland origin, leiomyoma, rhabdomyoma, lymphangioma, and hemangioma. Considering the size of the lesion an excisional biopsy was planned under local anesthesia. The mass was submucosal and once a mucosal flap was raised, the tumor was readily shelled out using blunt dissection (Figures 2,3 , and 4).

The procedure and postoperative period were uneventful. Histopathological examination of the surgical specimen revealed a schwannoma, mainly composed of Antoni A pattern with Verocay bodies and Antoni B (Figure 5).

The patient has not shown any recurrence in follow-up period of 1 year.

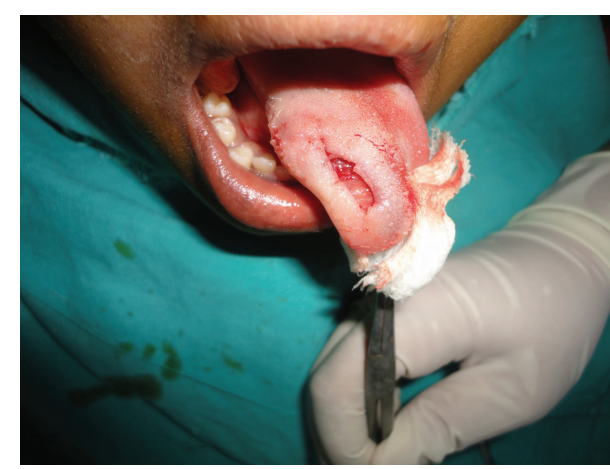

FIgURE 3: Complete excision.

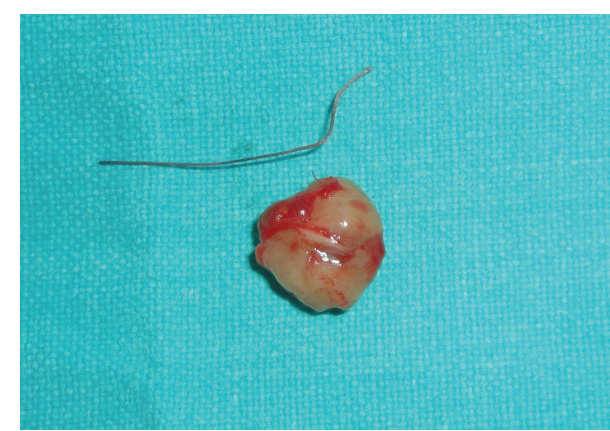

Figure 4: Excised mass.

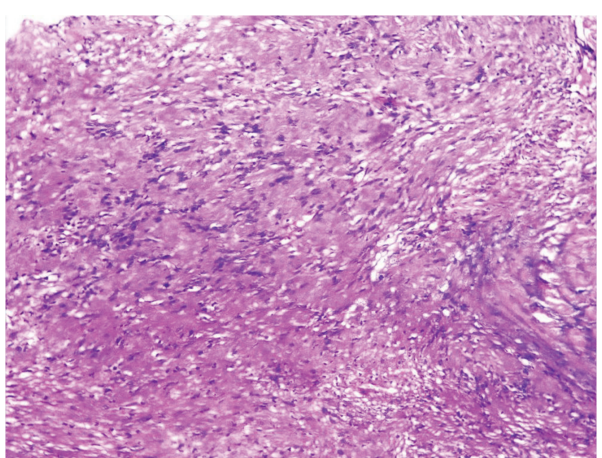

FIGURE 5: Spindle-shape neural cells arranged in Antoni A pattern with Verocay bodies.

\section{Discussion}

Almost a third of all schwannomas occurs in the head and neck region, but intraoral schwannomas are rare and account for $1 \%$ of the tumors growing in this region [4]. Because of their rarity, schwannomas are not generally part of the differential diagnosis of oral cavity lesions. Although the tongue is one of the most common tumour locations in the mouth, only 44 cases of lingual schwannoma have been reported in the English literature in the last 20 years [9]. However, on exploring PubMed we found 44 cases of lingual schwannoma reported in English literature in the past two decades (Table 1). 
TABLE 1: Demographic characteristic of cases reported in past 20 years' literature.

\begin{tabular}{|c|c|c|c|c|}
\hline Name of author(s) and year of publication & Age (years)/sex & Site of occurrence & Surgical approach & $\begin{array}{l}\text { Follow-up } \\
\text { (in months) }\end{array}$ \\
\hline \multirow{2}{*}{ López and Ballestin, 1993 [12] } & $\mathrm{M} / 24$ & Tongue & Transoral & \\
\hline & $\mathrm{M} / 33$ & Tongue & Transoral & \\
\hline de Bree et al., 2000 [13] & $\mathrm{F} / 24$ & Base of tongue & Submandibular & \\
\hline \multirow{2}{*}{ Pfeifle et al., 2001 [5] } & $\mathrm{M} / 18$ & Tongue & Transoral & \\
\hline & $\mathrm{F} / 30$ & Tongue & Transoral & \\
\hline Mevio et al., 2003 [14] & $\mathrm{F} / 35$ & Tongue & Tran oral & \\
\hline Bassichis and McClay, 2004 [15] & $\mathrm{M} / 9$ & Base of tongue & Transoral & 60 \\
\hline Cinar et al., 2004 [10] & $\mathrm{M} / 7$ & Tongue & Transoral & \\
\hline Nakasato et al., 2005 [16] & $\mathrm{F} / 9$ & Base of tongue & Transoral & 17 \\
\hline Hwang et al., 2005 [2] & $\mathrm{M} / 23$ & Tongue & Transoral & 6 \\
\hline Vafiadis et al., 2005 [17] & $\mathrm{M} / 18$ & Tongue & Transoral & 36 \\
\hline Ying et al., 2006 [18] & $\mathrm{F} / 26$ & Base of tongue & Transoral & \\
\hline \multirow{10}{*}{ Hsu et al., 2006 [19] } & $\mathrm{M} / 20$ & Base of tongue & Transoral & 3 \\
\hline & $\mathrm{M} / 45$ & Tongue & Transoral & 203 \\
\hline & $\mathrm{F} / 12$ & Tongue & Transoral & 13 \\
\hline & $\mathrm{M} / 38$ & Tongue & Transoral & 135 \\
\hline & $\mathrm{F} / 15$ & Tongue & Transoral & 136 \\
\hline & $\mathrm{M} / 25$ & Tongue & Transoral & 28 \\
\hline & $\mathrm{F} / 32$ & Base of tongue & Transoral & 63 \\
\hline & $\mathrm{M} / 9$ & Tongue & Transoral & 56 \\
\hline & $\mathrm{F} / 39$ & Base of tongue & Transhyoid & 23 \\
\hline & $\mathrm{F} / 39$ & Tongue & Transoral & 137 \\
\hline Mehrzad et al., 2006 [20] & $\mathrm{M} / 49$ & Base of tongue & Transoral $\left(\mathrm{CO}_{2}\right.$ LASER $)$ & 3 \\
\hline Enoz et al., 2006 [11] & $\mathrm{M} / 7$ & Tongue & Transoral & 60 \\
\hline Patnayak et al., 2007 [21] & $\mathrm{F} / 45$ & Tongue & Transoral & \\
\hline Ballesteros et al., 2007 [22] & $\mathrm{F} / 31$ & Base of tongue & Transoral $\left(\mathrm{CO}_{2}\right.$ LASER $)$ & \\
\hline \multirow{2}{*}{ Batra et al., 2007 [23] } & $\mathrm{M} / 33$ & Base of tongue & Transoral & 6 \\
\hline & $\mathrm{M} / 33$ & Base of tongue & Transoral & 9 \\
\hline Sawhney et al., 2008 [6] & $\mathrm{F} / 37$ & Base of tongue & Submandibular & \\
\hline Ferreti Bonan et al., 2008 [24] & $\mathrm{F} / 46$ & Tongue & Transoral & 12 \\
\hline Pereira et al., 2008 [25] & $\mathrm{M} / 12$ & Tongue & Transoral & 12 \\
\hline \multirow{2}{*}{ Cohen and Wang, 2009 [7] } & $\mathrm{M} / 77$ & Tongue & Transoral & \\
\hline & $\mathrm{F} / 19$ & Tongue & Transoral & \\
\hline Gupta et al., 2009 [26] & $\mathrm{F} / 18$ & Tongue & Transoral & \\
\hline Karaca et al., 2010 [27] & $\mathrm{F} / 13$ & Tongue & Transoral & 12 \\
\hline Naidu and Sinha 2010 [28] & $\mathrm{M} / 12$ & Tongue & Transoral & 3 \\
\hline Lukšić et al., 2011 [29] & $\mathrm{M} / 10$ & Tongue & Transoral & 60 \\
\hline Nisa et al., 2011 [30] & $\mathrm{F} / 38$ & Tongue & Transoral & \\
\hline Husain et al., 2011 [31] & $\mathrm{F} / 10$ & Tongue & Transoral & 12 \\
\hline Jeffcoat et al., 2010 [32] & $\mathrm{M} / 68$ & Tongue & Transoral & \\
\hline Catalfamo et al., 2011 [33] & $\mathrm{M} / 28$ & Tongue & Transoral & \\
\hline Manna et al., 2012 [34] & $\mathrm{M} / 15$ & Tongue & Transoral & \\
\hline Lira et al., 2013 [35] & $\mathrm{F} / 28$ & Tongue & Transoral & \\
\hline Moreno-García et al., 2014 [36] & $\mathrm{F} / 13$ & Tongue & Transoral & 12 \\
\hline
\end{tabular}


The mean age at diagnosis was 27 years. The age groups most affected were the 2nd (29.54\%), 3rd (18.18\%), and 4th (25\%) decades of life. There was no gender predisposition. Two-thirds of tumours (i.e., 32) arose in the tongue with the remaining one-third (i.e., 12) affecting the tongue base. Standard treatment was transoral excision, performed in $93.18 \%$ of cases. However, for tumours located at the base of the tongue, in 2 cases $\mathrm{CO}_{2}$ laser was used, and in three other cases, the approach was transcervical (two submandibular and one transhyoid). All tumours in the tongue were treated with simple transoral excision. There were no reports of recurrence. There are only 13 cases reported in the literature categorized in the pediatric age group. The youngest of them were reported by Cinar et al. [10] and Enoz et al. [11], of 7year-old, all being of male gender.

Lingual schwannoma can affect all age groups, being most commonly found between 30 and 40 years of age, without gender predisposition [6]. In this site, they usually appear as slow growing, progressive nodules, shown with symptoms that, when present, vary according to their size and location. The most common clinical presentation is a painless submucosal nodule with an average size of $2 \mathrm{~cm}$ [9]. Lingual schwannomas are rarely painful; they are usually noticed because of discomfort due to their position, such as difficulty in swallowing, chewing, and phonation [7].

Clinically, the schwannomas may be indistinguishable from other encapsulated benign tumors, so that biopsy and histological examination are essential to formulate a correct diagnosis. An excisional biopsy was performed in this patient, since treatment is exclusively surgical and usually enucleation of the mass is uncomplicated. In the present case, the patient did not present nerve injury after surgery, since the lesion was small and well defined. The option of complete resection was chosen on the basis of lesion form and size and to avoid recurrence.

The histological aspect of the lesion reported here was typical, consisting of a thin fibrous capsule and a tumor like proliferation formed by two types of tissue arrangements: Antoni type A and type B. The Antoni type A tissues are closely packed, forming bundles with elongated, palisaded nuclei. Free bands of amorphous substance between the rows of nuclei constitute the so called Verocay bodies which under electron microscope, appear to be composed of thin cytoplasmic processes with small amount of collagen and basal laminar material showing frequent redoubling, while in the Antoni B tissue it has less number of cells and less organization, where the fusiform cells are widely separated, dispersed in a loose and random fashion with a network of delicate reticulated fibers. Nuclear palisading distribution (typical of a schwannoma) was readily identifiable. The acid S-100 protein test was not performed, as the hematoxylineosin stained sections conclusively confirmed the diagnosis.

\section{Conclusion}

The schwannoma of the tongue is extremely rare, especially in children, and there are very few similar case reports in the present literature. Hereby we would like to add one new case of a schwannoma of the tongue as an example of a lesion which is often not taken into account during clinical practice or even considered as a possible diagnosis. Given the rarity of this lesion, a careful consideration is warranted as this may be clinically indistinguishable from fibroma, neurofibroma, and benign lesions like tumors of salivary gland origin, leiomyoma, rhabdomyoma, lymphangioma, and hemangioma. The definitive diagnosis requires a histopathological evaluation. Treatment is complete surgical excision of the lesion which does not result in any recurrence. The chance of malignant transformation of these tumors is unlikely.

\section{Conflict of Interests}

The authors declare that there is no conflict of interests regarding the publication of this paper.

\section{References}

[1] N. Zachariades, "Schwannoma of the oral cavity: review of the literature and report of a case," Journal of Oral Medicine, vol. 39, no. 1, pp. 41-43, 1984.

[2] K. Hwang, S. G. Kim, S. I. Ahn, and S. I. Lee, "Neurilemmoma of the tongue," Journal of Craniofacial Surgery, vol. 16, no. 5, pp. 859-861, 2005.

[3] H. K. Williams, H. Cannell, K. Silvester, and D. M. Williams, "Neurilemmoma of the head and neck," British Journal of Oral and Maxillofacial Surgery, vol. 31, no. 1, pp. 32-35, 1993.

[4] H. T. Anil, B. V. C. Gowda, S. Lakshmi, and S. R. Niveditha, "Schwannoma of the palatine tonsil," Journal of Laryngology and Otology, vol. 119, no. 7, pp. 570-572, 2005.

[5] R. Pfeifle, D. A. Baur, A. Paulino, and J. Helman, "Schwannoma of the tongue: report of 2 cases," Journal of Oral and Maxillofacial Surgery, vol. 59, no. 7, pp. 802-804, 2001.

[6] R. Sawhney, M. A. Carron, and R. H. Mathog, "Tongue base schwannoma: report, review, and unique surgical approach," American Journal of Otolaryngology_Head and Neck Medicine and Surgery, vol. 29, no. 2, pp. 119-122, 2008.

[7] M. Cohen and M. B. Wang, "Schwannoma of the tongue: two case reports and review of the literature," European Archives of Oto-Rhino-Laryngology, vol. 266, no. 11, pp. 1823-1829, 2009.

[8] T. K. Das Gupta and R. D. Brasfield, "Solitary malignant schwannoma," Annals of Surgery, vol. 171, no. 3, pp. 419-428, 1970.

[9] R. B. Lira, J. Gonçalves Filho, G. B. Carvalho, C. A. Pinto, and L. P. Kowalski, "Lingual schwannoma: case report and review of the literature," Acta Otorhinolaryngologica Italica, vol. 33, no. 2, pp. 137-140, 2013.

[10] F. Cinar, S. Cinar, and G. Harman, "Schwannoma of the tip of the tongue in a child," Plastic and Reconstructive Surgery, vol. 114, no. 6, pp. 1657-1658, 2004.

[11] M. Enoz, Y. Suoglu, and R. Ilhan, "Lingual schwannoma," Journal of Cancer Research and Therapeutics, vol. 2, no. 2, pp. 76-78, 2006.

[12] J. I. López and C. Ballestin, "Intraoral schwannoma. A clinicopathologic and immunohistochemical study of nine cases," Archives d'Anatomie et de Cytologie Pathologiques, vol. 41, no. 1, pp. 18-23, 1993.

[13] R. de Bree, G. Westerveld, and L. E. Smeele, "Submandibular approach for excision of a large schwannoma in the base of the 
tongue," European Archives of Oto-Rhino-Laryngology, vol. 257, no. 5, pp. 283-286, 2000.

[14] E. Mevio, E. Gorini, A. Lenzi, and L. Migliorini, "Schwannoma of the tongue: one case report," Revue de Laryngologie Otologie Rhinologie, vol. 123, no. 4, pp. 259-261, 2003.

[15] B. A. Bassichis and J. E. McClay, "Pedunculated neurilemmoma of the tongue base," Otolaryngology-Head and Neck Surgery, vol. 130, no. 5, pp. 639-641, 2004.

[16] T. Nakasato, Y. Kamada, S. Ehara, and Y. Miura, "Multilobular neurilemmoma of the tongue in a child," American Journal of Neuroradiology, vol. 26, no. 2, pp. 421-423, 2005.

[17] M. Vafiadis, A. Fiska, M. Panopoulou, and D. Assimakopoulos, "A clinical case report of a Schwannoma on the tip of the tongue," B-ENT, vol. 1, no. 4, pp. 201-204, 2005.

[18] Y. M. Ying, L. A. Zimmer, and E. N. Myers, "Base of tongue schwannoma: a case report," Laryngoscope, vol. 116, no. 7, pp. 1284-1287, 2006.

[19] Y. C. Hsu, C. F. Hwang, R. F. Hsu, F. Kuo, and C. Chien, "Schwannoma (neurilemmoma) of the tongue," Acta OtoLaryngologica, vol. 126, no. 8, pp. 861-865, 2006.

[20] H. Mehrzad, R. Persaud, N. Papadimitriou, S. Kaniyur, and G. Mochloulis, "Schwannoma of tongue base treated with transoral carbon dioxide laser," Lasers in Medical Science, vol. 21, no. 4, pp. 235-237, 2006.

[21] R. Patnayak, S. V. N. Anuradha, S. M. Uppin, C. Sundaram, G. S. N. Raju, and A. Jena, "Schwannoma of tongue-a case report and short review of literature," Acta Oncologica, vol. 46, no. 2, pp. 265-266, 2007.

[22] F. Ballesteros, I. Vilaseca, J. L. Blanch, A. Gaspa, and M. Bernal-Sprekelsen, "Base of tongue neurilemmoma: excision by transoral laser microsurgery," Acta Oto-Laryngologica, vol. 127, no. 9, pp. 1005-1007, 2007.

[23] K. Batra, A. K. Rai, N. Chaudhary, and S. Topno, "Two cases of neurilemmoma of the tongue," Ear, Nose and Throat Journal, vol. 86, no. 11, pp. 679-681, 2007.

[24] P. R. Ferreti Bonan, H. Martelli Jr., L. A. Nogueira dos Santos, V. Comini Mol, and O. Paes De Almeida, "Multinodular neurilemmoma of the tongue: a case report with differential immunohistochemical profile," Minerva Stomatologica, vol. 57, no. 1-2, pp. 71-75, 2008.

[25] L. J. Pereira, P. P. Pereira, P. dos Santos Jde, V. F. R. Filho, P. R. Dominguete, and A. A. Pereira, "Lingual schwannoma involving the posterior lateral border of the tongue in a young individual: case report," Journal of Clinical Pediatric Dentistry, vol. 33, no. 1, pp. 59-62, 2008.

[26] P. Gupta, A. Garg, K. K. Dhingra, D. Jain, K. Kohli, and N. Khurana, "Schwannoma tongue: a rare entity," ANZ Journal of Surgery, vol. 79, no. 1-2, pp. 93-94, 2009.

[27] C. T. Karaca, T. E. Habesoglu, B. Naiboglu et al., "Schwannoma of the tongue in a child," The American Journal of Otolaryngology-Head and Neck Medicine and Surgery, vol. 31, no. 1, pp. 46-48, 2010.

[28] G. S. Naidu and S. M. Sinha, "Schwannoma of the tongue: an unusual presentation in a child," Indian Journal of Dental Research, vol. 21, no. 3, pp. 457-459, 2010.

[29] I. Lukšić, D. Müller, M. Virag, S. Manojlović, and K. T. Ostović, "Schwannoma of the tongue in a child," Journal of CranioMaxillofacial Surgery, vol. 39, no. 6, pp. 441-444, 2011.

[30] L. Nisa, T. von Büren, A. Tiab, and R. Giger, "Giant plexiform schwannoma of the tongue," Case Reports in Otolaryngology, vol. 2011, Article ID 762524, 3 pages, 2011.
[31] S. Husain, M. R. M. Yunus, R. Ramli, and P. P. S. H. Athar, "Schwannoma of the tongue in a ten-year old child," Journal of the Pakistan Medical Association, vol. 61, no. 5, pp. 500-501, 2011.

[32] B. T. Jeffcoat, K. T. Pitman, A. S. Brown, and M. Baliga, "Schwannoma of the oral tongue," Laryngoscope, vol. 120, supplement 4, p. S154, 2010.

[33] L. Catalfamo, G. Lombardo, C. Nava et al., "Tongue schwannoma: clinicopathological findings," Journal of Craniofacial Surgery, vol. 22, no. 3, pp. 1158-1161, 2011.

[34] F. Manna, E. Barbi, F. Murru, and R. Bussani, "Lingual schwannoma in pediatric patients," Journal of Craniofacial Surgery, vol. 23, no. 5, pp. e454-e456, 2012.

[35] R. B. Lira, J. G. Filho, G. B. Carvalho, C. A. Pinto, and L. P. Kowalski, "Lingual schwannoma: case report and review of the literature," Acta Otorhinolaryngologica Italica, vol. 33, no. 2, pp. 137-140, 2013.

[36] C. Moreno-García, M. A. Pons-García, R. González-García, and F. Monje-Gil, "Schwannoma of tongue," Journal of Oral and Maxillofacial Surgery, vol. 13, no. 2, pp. 217-221, 2014. 


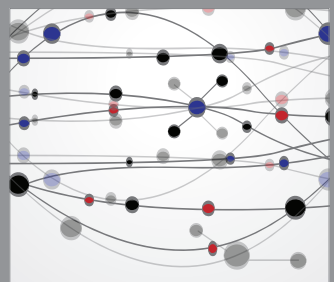

The Scientific World Journal
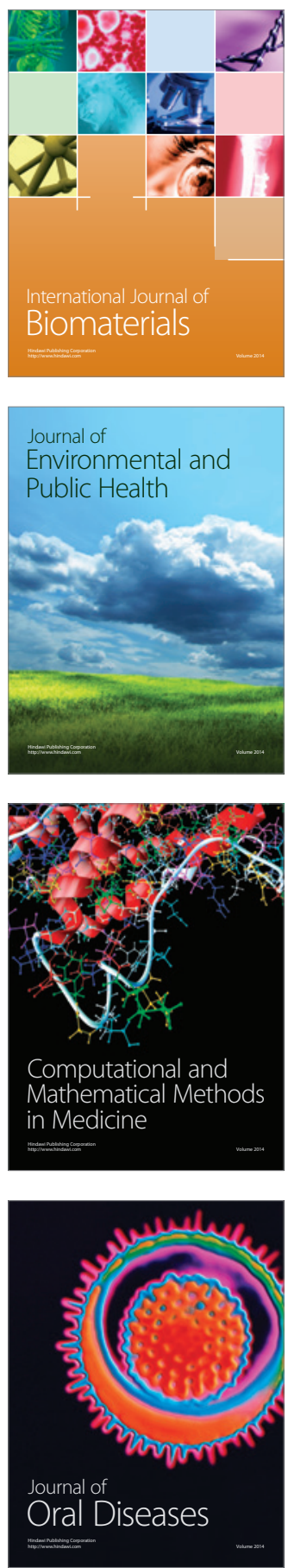
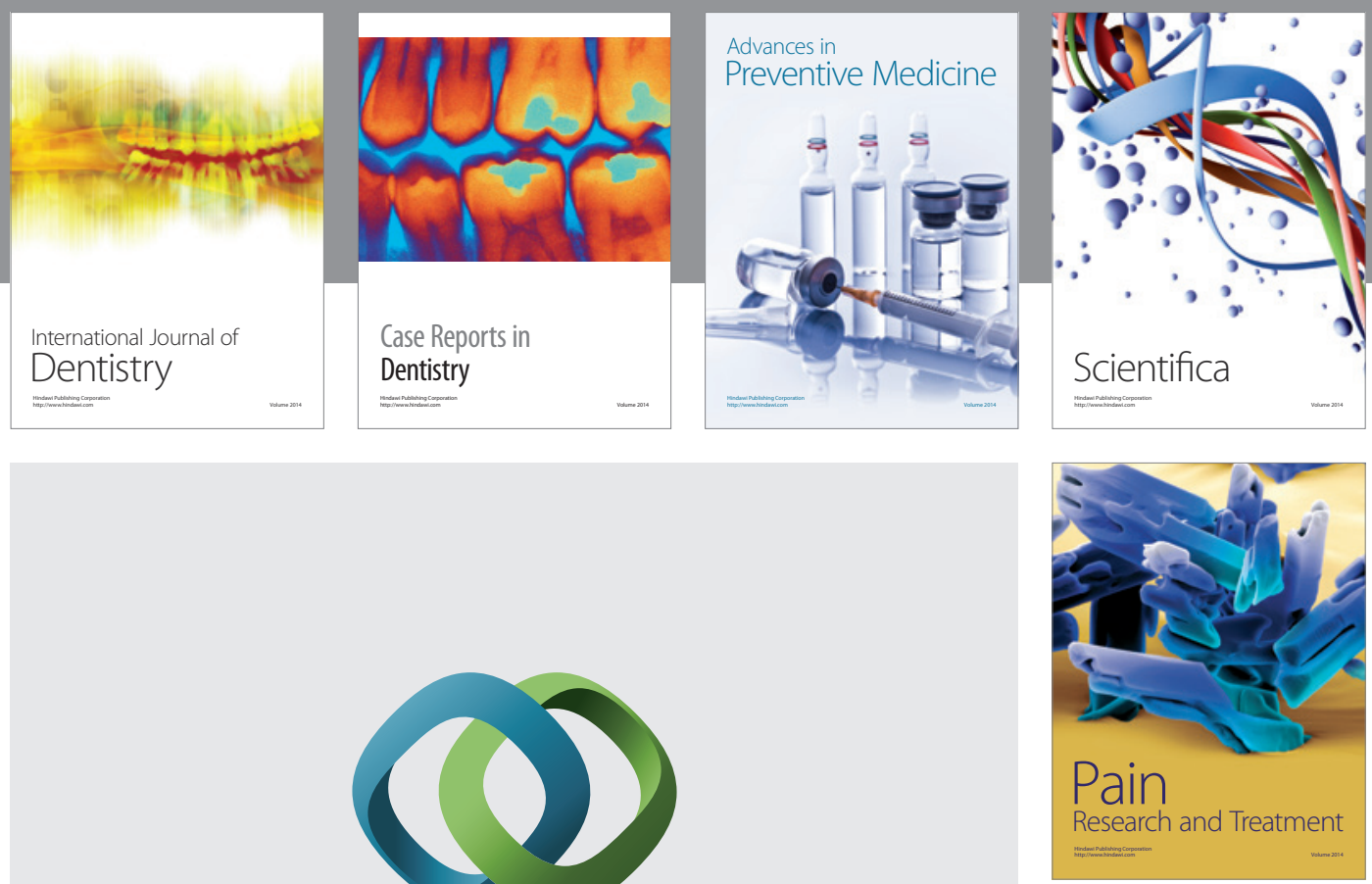

\section{Hindawi}

Submit your manuscripts at

http://www.hindawi.com
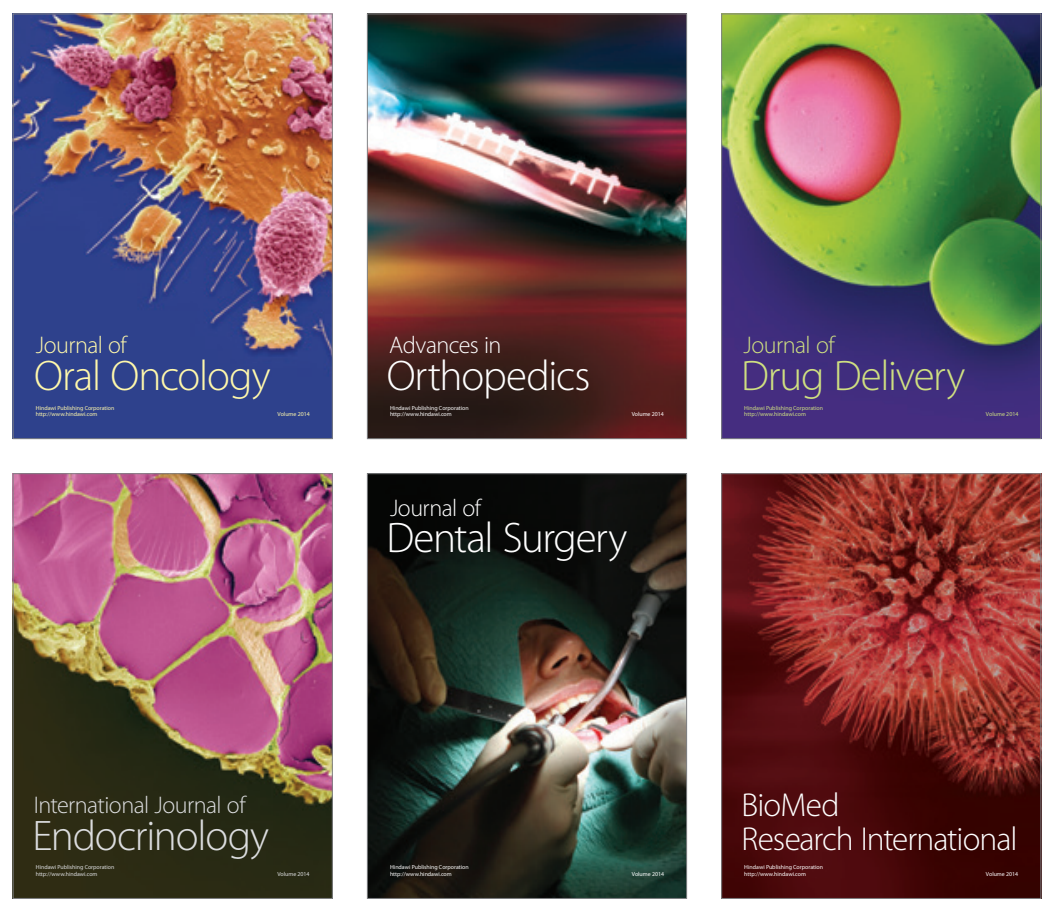

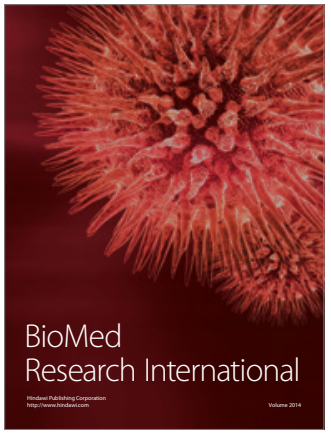

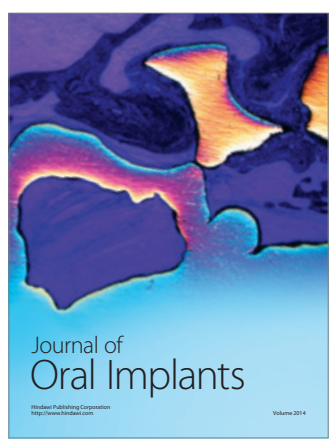
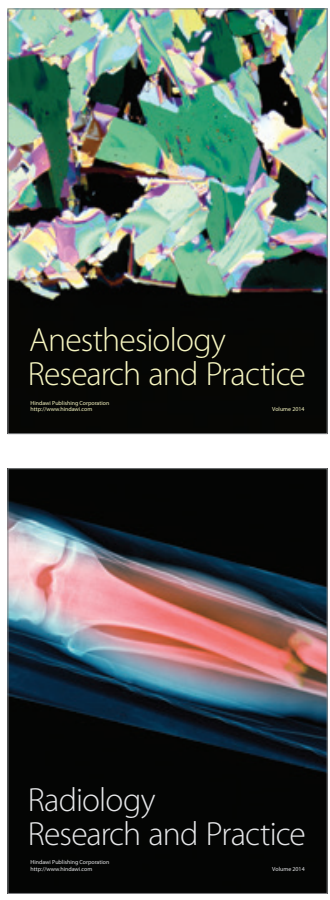